Global Conferences Series:

Sciences and Technology (GCSST), Volume 5, 2020

Seminar Nasional I Baristand Industri Padang (Semnas I BIPD)

DOI:https://doi.org/10.32698/GCS-SNIIBIPD3431

\title{
The formulation of lip balm by using gambir catechin (Uncaria gambir Roxb.) and its hedonic test
}

\section{Formulasi sediaan lip balm menggunakan katekin gambir (Uncaria gambir Roxb.) serta uji hedoniknya}

\author{
Sefrianita Kamal ${ }^{1}$, Sara Surya ${ }^{1}$, Ela Malita Krismon ${ }^{1}$ \\ ${ }^{1}$ Program Studi Farmasi, Universitas Dharma Andalas, Padang, Indonesia \\ E-mail: Seprianita.k@unidha.ac.id
}

\begin{abstract}
Lip balm is one of cosmetic material. It is used to moisturize lips to avoid them dry and chap easily. Catechins gambir are rich of flavonoids and tannins that have antioxidant and can moisturize the skin and reduce dryness of the lips. The purpose of this research was to formulate and test the effectiveness of lip balm by using catechin gambir. It used $0.5 \%, 1 \%$ and $1.5 \%$ concentration of catechin gambir. The testing included homogeneity test, irritation test, preference test, preparation stability test and testing the ability of lip balm preparations to moisturize lips in the tested volunteers by using the preparation every morning and night for 28 days. The results showed that all lip balm preparations were homogeneous, did not irritate the skin, stable in storage and the preference test was based on the panelists' assessment. The panelists prefer the lip balm formula 4 used 1.5\% concentration of catechin. Catechin gambir lip balm 1\% and 1.5\% were the best lip moisturizing effect after 28 days of use.
\end{abstract}

Keywords: formulation; lip balm; catechin gambir (Uncaria Gambir Roxb.); hedonic test

\begin{abstract}
Abstrak: Lip balm merupakan pelembab yang berfungsi untuk melembabkan bibir agar tidak mudah kering dan pecah. Keuntungan katekin sebagai bahan alami untuk menggantikan bahan sintetis karena dengan penggunaan di pasaran sekarang banyak menggunakan bahan yang mengandung kimia yang dapat membahayakan konsumen dalam memakai kosmetika. Katekin gambir yang kaya dengan flavonoid dan tanin yang berkhasiat sebagai antioksidan. Tujuan penelitian ini adalah untuk memformulasikan dan uji efektivitas sediaan lib balm menggunakan katekin gambir. Penelitian ini menggunakan katekin gambir dengan konsentrasi $0,5 \%, 1 \%$ dan 1,5\%. Evaluasi sediaan lip balm meliputi uji homogenitas, uji iritasi, uji hedonik (kesukaan), uji stabilitas sediaan dan pengujian kemampuan sediaan lip balm untuk melembabkan bibir pada sukarelawan yang diuji dengan menggunakan sediaan setiap pagi dan malam selama 28 hari lalu diukur kadar air bibir setiap minggu dengan menggunakan alat skin analyzer. Hasil penelitian diperoleh bahwa formula 4 sediaan lip balm homogen, tidak mengiritasi kulit, stabil dalam penyimpanan dan ujihedonik ( kesukaan) berdasarkan penilaian panelis menyukai sediaan lip balm formula 4 dengan menggunakan konsentrasi $1,5 \%$. Sediaan lip balm katekin gambir dengan konsentrasi 1,5\% dapat memberikan efek melembabkan bibir paling baik setelah 28 hari pemakaian dengan menggunakan alat skin analyzer.
\end{abstract}

Kata Kunci: formulasi; lip balm; katekin gambir (Uncaria Gambir Roxb.); uji hedonik

\section{PENDAHULUAN}

Kosmetika adalah bahan atau sediaan yang dimaksudkan untuk digunakan pada bagian luar tubuh manusia (epidermis, rambut, kuku, bibir dan organ genital bagian luar) atau gigi dan mukosa mulut terutama untuk membersihkan, mewangikan, mengubah penampilan atau memperbaiki bau badan atau melindungi atau memelihara tubuh pada kondisi baik (Menkes RI, 2010).

Copyright (C) 2020, the Authors. Published by Redwhite Press.

This is an open access article under the CC BY-NC license

(http://creativecommons.org/licenses/by-nc/4.0). 
Lip balm atau pelembab bibir merupakan sediaan kosmetika yang sering digunakan wanita. Komponen utamanya seperti lilin, lemak dan minyak dari ekstrak alami atau yang disintesis. Lip balm digunakan untuk mencegah terjadinya kekeringan dengan meningkatkan kelembaban bibir dan melindungi pengaruh buruk lingkungan pada bibir (Kwunsiriwong, 2016). Indonesia memiliki kekayaan sumber flora diantaranya dapat digunakan sebagai bahan alami untuk menggantikan bahan sintetis karena dengan penggunaan dipasaran sekarang banyak menggunakan bahan yang mengandung kimia yang dapat membahayakan konsumen dalam memakai kosmetika. Salah satu tanaman yang mempunyai potensi untuk dikembangkan antara lain berasal dari tanaman gambir karena kandungan flavonoid dari katekin yang sangat tinggi (BPOM RI, 2004). Gambir adalah ekstrak kering yang dibuat dari daun tumbuhan Uncaria gambir Roxb., termasuk dalam suku Rubiaceae yang mengandung katekin tidak kurang dari 90,0\% (Depkes RI, 2008). Senyawa katekin merupakan senyawa golongan polifenol yang berpotensi sebagai antioksidan. Katekin biasa disebut asam katekuat atau asam katekinat (Gumbira-Sa'id E, 2009).

Kandungan utama ekstrak gambir adalah katekin. Selain katekin, ekstrak gambir mengandung bermacam-macam komponen, antara lain asam kateku tanat 20-55\%, pirokatekol 20-30\%, gambir flouresen 1-3\%, kateku merah 35\%, quarsetin 2-4\%, fixed oil 1-2\%, dan wax 1-2\%. Kandungan katekin antara lain untuk pewarna dalam industri batik, penyamak kulit, ramuan makan sirih, sebagai obat untuk luka bakar, diare, disentri, sariawan dan bahan pembuatan permen (Isnawati, 2015). Penelitian sebelumnya yang sudah dilakukan berkaitan dengan aktivitas antioksidan dan antibakteri, berasal dari ekstrak etanol daun gambir sebagai antiseptik mulut, dan untuk kesehatan lainnya. Agar menghasilkan produk kosmetika yang alami, aman dan memberi kenyamanan bagi pengguna, maka peneliti tertarik melakukan penelitian menggunakan katekin pada formulasi pelembab bibir. Dengan penelitian berjudul "Formulasi sediaan Lip Balm mengunakan katekin gambir (Uncaria gambir Roxb)". Adapun dilakukan penelitian ini bertujuan untuk mengetahui sediaan pelembab bibir yang mengandung katekin gambir (Uncaria gambir Roxb.) sebagai peningkatan kelembaban bibir menjadi lebih baik selama empat minggu perawatan, sehingga hasil penelitian ini dapat digunakan sebagai sumber informasi bagi masyarakat dan sediaan tersebut dapat digunakan sebagai pelembab bibir.

\section{METODE}

Penelitian ini meliputi pembuatan sedian lip balm menggunakan katekigambir dengan konsentrasi 0,5\%, $1 \%$ dan 1,5\%. Pemeriksaan mutu fisik sediaan meliputi ujihomogenitas, uji stabilitas, uji iritasi, uji kesukaan, dan kemampuan sediaan melembabkan bibir menggunakan alat skin analyzer. Katekin murni (98,88 \%) diperoleh dari Politeknik ATI Padang dan diperiksa kadar katekin serta serapan Uvnya di UPT Sumber Daya Hayati Universitas Andalas.

\section{Alat dan Bahan}

Alat-alat yang digunakan dalam penelitian ini antara lain timbangan analitik (KERN EG ${ }^{\circledR}$ Instrument), kertas perkamen, cawan penguap, spatel, sendok tanduk, hot plate, lumpang, stamfer, batang pengaduk, gelas arloji, skin analyzer(Digital Mousture Content Analyzer SK-8), dan wadah lip balm. Bahan-bahan yang digunakan dalam penelitian ini adalah katekin, cera alba, lanolin, oleum rosae, propilen glikol, pewarna makanan (Red Bell), setil alkohol, paraffin cair dan metil paraben (nipagin).

Tabel 1. Formula sediaan lip balm menggunakan katekin gambir

\begin{tabular}{llcccc}
\hline No. & Bahan & \multicolumn{3}{c}{ Konsentrasi (\%) } \\
& & F0 & F1 & F2 & F3 \\
\hline $\mathbf{1}$ & Katekin & - & 0,5 & 1 & 1,5 \\
$\mathbf{2}$ & Etil alkohol & 10 & 10 & 10 & 10 \\
$\mathbf{3}$ & Lanolin & 10,5 & 10,5 & 10,5 & 10,5 \\
$\mathbf{4}$ & Cera Alba & 18 & 18 & 18 & 18 \\
$\mathbf{5}$ & Propilen Glikol & 10 & 10 & 10 & 10 \\
$\mathbf{6}$ & Oleum Rosae & 0,4 & 0,4 & 0,4 & 0,4 \\
$\mathbf{7}$ & Nipagin & 0,5 & 0,5 & 0,5 & 0,5 \\
$\mathbf{8}$ & Pewarna & $\mathrm{qs}$ & $\mathrm{qs}$ & $\mathrm{qs}$ & $\mathrm{qs}$ \\
$\mathbf{9}$ & Paraffin Cair ad & 100 & 100 & 100 & 100 \\
\hline
\end{tabular}

\section{Pembuatan Lip Balm}

Timbang semua bahan sesuai formula diatas. Katekin digerus didalam lumpang sampai halus. Ditambahkan nipagin kemudian gerus, larutkan dalam propil glikol. Setelah katekin gambir dan nipagin larut, 
kemudian campuran tersebut, ditambahkan paraffin liquidum. Lalu ditambahkan pewarna secukupnya, diaduk hingga homogen (campuran A). Cera alba dimasukkan kedalam cawan penguap, kemudian dileburkan di atas hot plate temperature $62-64^{\circ} \mathrm{C}$, kemudian masukkan setil35uncan35 dan lanolin sampai cair. Setelah cair dimasukan hasil leburan ke dalam lumpang yang berisi campuran A digerus sampai homogen dan dimasukan oleum rosae sedikit demi sedikit sampai homogen. Campuran A dan B yang telah 35uncan35y dimasukkan ke dalam wadah lip balm yang telah dioleskan parafin lalu dibiarkan sampai membeku (Nurul et al, 2019).

\section{Evaluasi Sediaan Lip Balm}

Pemeriksaan mutu fisik dilakukan terhadap masing-masing sediaan pelembab bibir. Pemeriksaan mutu fisik antara lain: pengujian homogenitas, uji stabilitas sediaan, uji iritasi, uji kesukaan (Hedonic Test) dan kemampuan sediaan untuk melembabkan bibir menggunakan alat skin analyzer (Risnawati, dkk., 2012).

\section{Uji Homogenitas}

Pemeriksaan homogenitas dengan menggunakan kaca objek. Sejumah sampel dioleskan diatas kaca objek, kemudian ditutup dan ditekan dengan kaca objek yang lain. Sediaan harus menunjukkan susunan yang homogen dan tidak terlihat adanya bintik-bintik pewarna atau tidak berbintik (Risnawati, et al., 2012).

\section{Uji Stabilitas}

Pemeriksaan stabilitas sediaan dilakukan terhadap adanya perubahan bentuk, warna dan bau dari sediaan lip balm. Dilakukan terhadap masing masing sediaan selama penyimpanan pada suhu kamar pada hari ke 0, 7, 14, 21 hingga hari ke-28 (Syakdiah, 2018).

\section{Uji Iritasi}

Teknik yang digunakan pada uji iritasi ini adalah uji tempel terbuka (Patch Test) pada lengan bawah bagian dalam terhadap 12 orang percobaan selama 6 jam. Uji tempel terbuka dilakukan dengan mengoleskan sediaan yang dibuat pada lokasi lekatan, dibiarkan terbuka dan diamati apa yang terjadi (Risnawati, et al., 2012).

\section{Uji Hedonik (Kesukaan)}

Setiap panelis diminta untuk mengoleskan lip balm yang dibuat dengan berbagai konsentrasi katekin gambir pada bibir panelis. Kemudian panelis memilih variasi formula mana yang paling disukai. Parameter pengamatan pada uji kesukaan adalah kemudahan pengolesan, aroma, homogenitas dan kelembapan yang dirasakan pada bibir. Kemudian dihitung persentase kesukaan terhadap masing-masing sediaan (Hutami et al., 2014)

\section{Kemampuan Sediaan Melembabkan Bibir}

Pengujian efektivitas pelembab bibir dilakukan terhadap sukarelawan sebanyak 12 orang. Semua sukarelawan diukur kondisi awal kulit bibir pada area uji yang akan dioleskan pelembab bibir. Pengujian yang dilakukan adalah uji kadar air (moisture), dengan menggunakan alat skin analyzer. Perawatan mulai dilakukan dengan mengoles pelembab bibir hingga merata pada bibir. Pelembab bibir dioles berdasarkan kelompok yang telah ditetapkan di atas. Perubahan kondisi kulit bibir diukur saat sebelum aplikasi dan setelah aplikasi pelembab bibir setiap 7, 14, 21 dan 28 hari dengan menggunakan alat skin analyzer (Putri Handika, 2018).

\section{HASIL DAN PEMBAHASAN \\ Pemeriksaan Homogenitas}

Hasil pemeriksaan homogenitas terhadap sediaan lip balm katekin gambir dengan konsentrasi $0,5 \%$, $1 \%$ dan 1,5\% menunjukkan bahwa semua sediaan tidak memperlihatkan adanya butir-butir kasar pada saat sediaan dioleskan pada kaca transparan. Hal ini menunjukkan bahwa sediaan yang dibuat memiliki susunan yang homogen (Ditjen POM RI., 1979). 


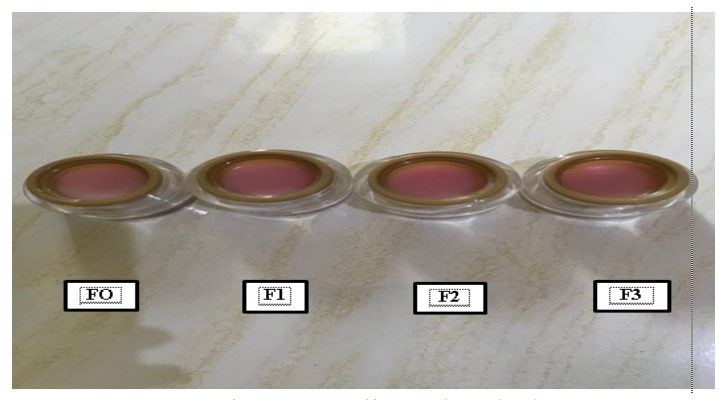

Gambar 1. Sediaan lip balm

\section{Hasil Uji Stabilitas}

Hasil uji stabilitas sediaan lip balm menunjukkan bahwa sediaan yang dibuat tetap stabil dalam penyimpanan pada suhu kamar selama 28 hari pengamatan. Parameter yang diamati dalam uji kestabilan fisik ini meliputi perubahan bentuk, warna dan bau sediaan. Berdasarkan hasil pengamatan bentuk, diketahui bahwa seluruh sediaan lip balm yang dibuat memiliki bentuk dan konsistensi yang baik yaitu tidak meleleh pada penyimpanan suhu kamar. Warna dan bau lip balm juga stabil dalam penyimpanan selama 28 hari pengamatan pada suhu kamar.

\section{Hasil Uji Iritasi}

Hasil pengujian menunjukkan bahwa semua panelis memberikan reaksi negatif terhadap parameter reaksi iritasi, sehingga sediaan lip balm yang diujikan dapat dikatakan tidak mengiritasi merupakan sediaan yang diharapkan karena akan memberikan rasa aman bagi pengguna.

\section{Hasil Uji Hedonik (Kesukaan)}

Berdasarkan hasil pengujian grafik nilai kesukan terhadap 30 panelis terhadap sediaan lip balm katekin pada keempat formula yang paling banyak disukai panelis yaitu F3 dengan mengandung 1,5\% katekin gambir. Data yang diperoleh kemudian dianalisis dengan uji statistika Kolmogorov-smirnov test, hasil One Sample Kolmogorov-smirnov test terlihat data terdistribusi tidak normal dengan nilai $(\mathrm{p}<0,05)$. Kemudian dilanjutkan dengan uji kruskal wallis, hasil dari uji kruskal wallis dari keempat formula tidak berpengaruh signifikansi karena nilai $(\mathrm{p}>0,05)$ (Khairunnisa, et al., 2012).

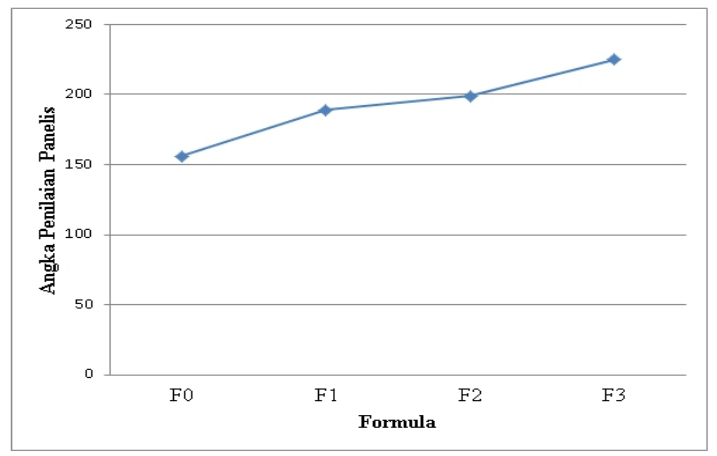

Gambar 2. Grafik uji hedonic

\section{Kemampuan Sedian Melembabkan Bibir}

Hasil pengujian efektivitas kelembapan bibir dilakukan terhadap 12 orang panelis. Pengujian dengan membandingkan keadaaan bibir sebelum dan sesudah pemakaian sediaan dengan nilai parameter kelembapan (moisture). Semua panelis diukur terlebih dahulu kondisi kelembapan bibir awal/sebelum perlakuan dengan menggunakan skin analyzer. Data yang diperoleh pada hasil kelembapan bibir akan dianalisis dengan menggunakan program statistik dengan metode analisis anova dua arah kemudian dilanjutkan dengan Duncan's.

Data pada uji efektifitas sediaan menunjukkan selama empat minggu perawatan dengan pemberian sedian lip balm setiap hari pada pagi dan malam secara rutin, kelembapan pada bibir panelis mengalami peningkatan terutama pada $\mathrm{F} 3$ dengan rata-rata persen pemulihan sebesar $30.89 \%$. F0 mengalami persen pemulihan $3.18 \%$ dengan melembabkan bibir.

Data yang diperoleh pada hasil kelembaban bibir akan dianalisis dengan menggunakan program statistik metode (ANOVA) dua arah. Efektifitas kelembaban katekin gambir dipengaruhi secara signifikan 
oleh formula, waktu dan interaksi antara keduanya $(\mathrm{P}<0.05)$. Pada grafik pengaruh pemakaian lip balm dari katekin gambir terhadap kelembapan bibir panelis selama empat minggu perawatan mengalami peningkatan F0 3.81\%, F1 11.03\%, F2 16.74\%, F3 30.89\%.

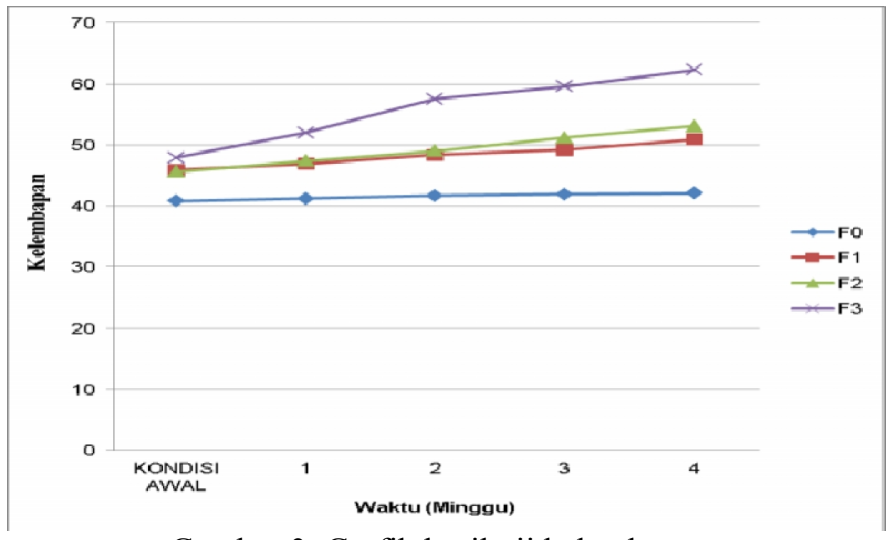

Gambar 3. Grafik hasil uji kelembapan

Peningkatan kadar air pada bibir sejalan dengan peningkatan konsentrasi katekin gambir yang digunakan. Konsentrasi katekin yang semakin tinggi memberikan persentase peningkatan kadar air yang semakin besar yang artinya bibir akan semakin lembab. Bibir yang memiliki kelembaban yang tinggi akan lebih cenderung sulit untuk mengalami kerusakan seperti kering dan pecah-pecah walaupun berada pada kondisi lingkungan yang ekstrim.

Kemampuan lip balm dalam mempertahankan kelembaban didukung dengan adanya bahan-bahan yang terkandung di dalamnya. Sebagai bahan dasar pembuatan lip balm, cera alba, setil alkohol dan paraffin cair, dalam penelitian ini katekin gambir memiliki kemampuan dalam menahan penguapan air, karenaa danya senyawa flavonoid sebagai antioksidan dan ini merupakan salah satu faktor dalam aktivitas lip balm untuk mempertahankan kelembaban bibir (Nazliniwaty et al., 2019).

Tabel 2. Tabel kadar air pada bibir selama pengujian

\begin{tabular}{lllllll}
\hline Formula & Panelis & KondisiAwal & \multicolumn{4}{c}{ Waktu Perawatan Setelah Minggu Ke - } \\
& & & 1 & 2 & 3 & 4 \\
\hline Fo & 1 & 32.1 & 32.3 & 33.3 & 33.3 & 33.6 \\
& 2 & 32.4 & 33.2 & 33.6 & 34 & 34.2 \\
& 3 & 58 & 58.3 & 58.2 & 58.5 & 58.7 \\
F1 & 1 & 40.2 & 41.4 & 42.8 & 43.6 & 44.2 \\
& 2 & 52.2 & 53.4 & 54.7 & 55.2 & 56.9 \\
F2 & 3 & 45.3 & 46 & 47.8 & 49 & 51.7 \\
& 1 & 42.3 & 44.6 & 46.4 & 48.2 & 50.2 \\
& 2 & 51.1 & 52 & 53.3 & 55.7 & 57.8 \\
& 3 & 43.4 & 45.7 & 47.3 & 49.8 & 51.2 \\
& 1 & 45.6 & 49.3 & 58.2 & 60.9 & 63.7 \\
& 2 & 48.5 & 53.4 & 57.9 & 59.3 & 62.3 \\
\end{tabular}

Keterangan: Dehidrasi 0-29, Normal 30-50, Hidrasi/ Lembab 51-100 (Aramo, 2012).

\section{SIMPULAN}

Katekin gambir dapat dimanfaatkan sebagai pelembab bibir dalam sediaan lip balm. Semakin tinggi konsentrasi katekin gambir memberikan persentase peningkatan kadar air 63\% pada $\mathrm{F} 4$ yang paling bagus memberikan kelembapan (dehidrasi 0-29, normal 30-50, hidrasi/lembab 51-100) yang semakin tinggi dan dapat meningkatkan kadar air bibir dari dehidrasi menjadi normal. Menurut uji statistika tidak berpengaruh signifikan terhadap formula 4 . 


\section{UCAPAN TERIMA KASIH}

Terima kasih untuk LPPM Universitas Dharma Andalas yang telah mendanai penelitian ini.

\section{REFERENSI}

BPOM. 2004. Monografi ekstraksi tumbuhan obat Indonesia vol 2. Jakarta: Direktorat Jenderal Pengawasan Obat dan Makanan. Hal 55-9

Departemen Kesehatan RI. 2008. Farmakope Herbal Indonesia. Jakarta: Departemen Kesehatan RI.

Ditjen POM. 1985. Formularium Kosmetik Indonesia. Jakarta: Departemen Kesehatan RI. Hal. 71, 83, 85, 86, 103-105, 195-197

Gumbira-Sa'id E. 2009. Review of agroindustrial strategic studies, researches and development in Indonesia: the case of oil palm, cacao and gambir. J TekInd Pert. 19 (1): 45-55.

Hutami, R.A.P., Joshita, D., Abdul, M. 2014. Pemanfaatan Ekstrak Kelopak Bunga Rosella (Hibiscus sabdariffa L.) Sebagai Pewarna dan natioksidan Alami dalam Formulasi Lipstik dan Sediaan Oles Bibir. Universitas Indonesia.

Isnawati A. 2015. Analisa Kualitatif dan kuantitatif senyawa katekin dan kuersetin pada 3 mutu ekstrak gambir. Pusat Penilitian dan Pengembangan Biomedis dan Farmasi. Jakarta

Khairunnisa, Hari,R.T., dan Dadang, I.H., 2012. Statistika farmasi aplikasi menggunakan SPSS. Medan: USU Press

Kwunsiriwong, S. 2016. The Study on the Development and Processing Transfer of Lip Balm Products from Virgin Coconut Oil: A Case Study. Official Conference Proceedings of The Asian Conference on Sustainability, Energy \& the Environment 2016. Thailand: The International Academic Forum. Hal. $1-4$

Menkes RI. 2010. Permenkes RI tentang Notifikasi Kosmetika. PERMENKES. Jakarta.

Nazliniwaty, Lia L., dan Mega W. Pemanfaatan Ekstrak Kulit Buah Delima (Punicagranatum L.) dalam Formulasi Sediaan Lip Balm. Medan. Jurnal Jamu Indonesia. 2019 ; 4(3):87-92.

Nurul AY., Besse H., Indah AL., Amriani S. 2019. Formulasidan evaluasi lip balm liofilisat buah tomat (Solanum lycopersicum L.) sebagai pelembab bibir. Sekolah Tinggi Ilmu Farmasi. Makasar

Risnawati, Naziniwaty.,dan Purba, Djendakita. 2012, Formulasi lipstik menggunakan ekstrak biji coklat (Theobroma cacao L) sebagai pewarna. Journal of Pharmaceutics and Pharmacology.1 : 78-86

Syakdiah, khalimatu. 2018. Formulasi sediaan lip balm yang mengandung minyak buah merah (Red fruid oil) sebagai pelembab bibir. Fakultas Farmasi USU. Medan.

Putri Handika Hasan. 2018. Formulasi sediaan pelembab bibir minyak biji anggur (Grapseed Oil). Fakultas Farmasi USU. 